\title{
A NEW LEAF-MINER OF COTTON IN PORTO RICO
}

\section{(NEPTICULA GOSSYPII new species)}

By W. T. M. Forbes ${ }^{1}$ and M. D. Leonard ${ }^{2}$

\section{INTRODUCTION}

On March 6, 1930 a small cotton field was found near Juana Díaz in which the leaves were severely infested by a leaf-miner. $\Lambda$ minute moth which appeared black-and-white banded to the naked eye, was noticed on a number of the leaves and judged to be associated with the trouble. Facilities were lacking at the time for collecting and preserving specimens, but a quantity of the mined leaves were gathered.

During the course of that day and the next, a number of cotton fields were carefully examined in the vicinity of Ponce, Tallaboa, Yauco and Sabana Grande, and the leaf-miner was found to be present in all, with one or two exceptions, in greater or less numbers. Most of the mines seemed to be empty and moths were not again observed, though they are so small as to have been easily overlooked.

On March 8th several fields of cotton were examined in the vicinity of Arecibo and Camuy on the North Coast. The cotton here was all young, being only a few inches high. Two or three leaves only were found showing a small mine or two apiece.

Upon reaching the laboratory in Río Piedras on the 10th it was found that the leaves had either badly moulded or had dried. Three greenish lepidopterous larvae, however, were dissected from the end of fresh mines and one naked pale greenish pupa was found on the surface of a leaf. These all died in a day or two.

No reference to a leaf-miner in cotton could be found in literature available nor any record of such in the files of the Insular Experiment Station. Nor was a leaf-miner mentioned in the paper on "Cotton Insects of Porto Rico" by E. G. Smyth, Ent. News 31: 121-125, 1920.

Further opportunity to collect additional material did not present itself until April 5th, 1930 when in company with Dr. J. G. Needham of Cornell University a field of cotton was visited near the one firstmentioned near Juana Díaz. The work of the leaf-miner was ex-

${ }^{2}$ Of the Department of Entomology, Cornell University, Ithaca, N. Y.

2 Of the Division of Entomology, Insular Experimental Station, Río Piedras, Porto Rico. 
ceedingly abundant but all the mines examined were empty and no moths could be found. Another field just north of Villalba was found to be much more lightly infested but here three or four mines were found containing larvae.

From these two fields a considerable number of leaves was brought back to the laboratory. It was not possible to examine them carefully until the 8th. On this date a number of cocoons were found, mostly on the lower surface of the leaves, and three or four larvae were dissected from the mines. The cocoons were confined in shell vials and on the 15th eight moths were found, a couple of these undoubtedly having emerged the day before, since they were already dead. On April 16th four more moths had emerged and on the 17th three additional adults were obtained.

Further field observations were made in two eotton fields on April 18th near Guayanilla. In one, a dry field where no new leaves were being put out the mines were old and apparently all deserted. Every leaf examined, however, had been infested, many having numerous mines. In the other field the plants were producing new foliage. Here the condition of the old leaves were as in the other field: the new leaves showed a moderate number of fresh mines.

\section{Food Plants and Origin}

The cotton referred to in this discussion is all Sea Island cotton (Gossypium barbadense L.). This type is being increasingly grown commercially in Porto Rico and is found by many farmers to be a profitable crop, especially desirable in some cases as a substitute crop on land which will not produce a profitable crop of sugar-cane. There was during the growing season of 1929-1930 about 14,000 acres of Sea Island Cotton in Porto Rico, divided between about 4,000 acres on the South Coast and about 10,000 on the North Coast.

On April 24 and again on May 20 a number of fields were examined on the North Coast throughout the length of the cotton growing belt. Altho by the latter date a number were well along towards maturity and the plants large no evidence of the presence of the leaf-miner could be found. On May 21st several fields were examined on the South Coast. The plants were all old and the erop had apparently matured and been for the most part picked. Abundant evidence was present of earlier infestation, but even where green, fairly new foliage was present, no new infestation could be found. The same condition obtained about ten days later. Apparently there 
is a distinct season of activity and non-activity of the insect in relation to the cotton on the South Coast.

Casual search on tree cotton (Gossypium hirsutum L.) has failed so far to disclose evidence of this leaf-miner on the Island of Porto Rico. On April 30th, however, we examined several tree cotton plants near Puerto Real on Vieques Island. One leaf had a small mine which appeared to be characteristic of this species. We have as yet had little opportunity to search for it in other species of Gossypium known to occur in Porto Rico, or in other Malvaceae of which there are several species occurring here.

It cannot be determined at present whether this leaf miner is indigenous to Porto Rico or not. So far as we can ascertain, no Nepticula has yet been recorded from the West Indies, and no Nepticula has yet been bred from cotton in any part of the world. It seems unlikely that an insect whose work is so conspicuous on a crop that has been so earefully observed by official entomologists in the past, should have been entirely overlooked, so there is a possibility that the species has recently come over from some other Malvaceous food, or from some other part of the world. The two-banded species of Nepticula seem to be most characteristic of the New World, however, and the probability is that the species is actually indigenous to the Antilles or to Central America. It should be sought for in the other cotton growing areas of this zone, especially in regions where cotton is grown in small amounts or semicommercially among native vegetation.

\section{Description of the Stages}

THE EGG (PL. XV, FIG. 6)

Unhatched eggs have not been found, but the egg-shell is as follows: about .17 mm. in length and about $.14 \mathrm{~mm}$. at greatest width; broadly elliptical, somewhat convex on free surface, shining, translucent white, and without noticeable sculpture under the high power binocular.

THE LARVAE (PL. XV, FIG. 2)

Length $2.5 \mathrm{~mm}$; green with the chitinized parts of the head pale brownish; somewhat flattened; the legs represented by high conical projections or lobes on the meso- and metathorax and on the 2nd to 7 th segments of the abdomen; first and last 3 abdominal segments noticeably reduced in size; the structure of the head and the arrangement of the setae are as usual in the family. 
THE PUPA (PL. XV, FIGS. 4 AND 5)

Length, 1.3-1.5 mm.; color pale green, the abdomen somewhat darker, without markings; cuticle thin, soft and transparent; of a modified incomplete type, stout and flattened; wings and hind legs reaching to end of body; antennæ half as long; tongue rudimentary; appendages soldered but not strongly so, with all their parts easily recognizable; prothorax much narrower than head in dorsal view; abdominal segments effectively immovable; no obvious setae or spines except on the last segment which has a larger anterior pair of projecting teeth and a smaller posterior pair; last abdominal segment truneate and slightly bifid behind; middle abdominal segments each with a transverse row of spiracles, only distinctly visible on the cast pupashell; scape very large, covering the eye except a small ventral portion; maxillary palpi conspicuous, transverse, extending behind the eye from antenna to maxilla; labial palpi short, completely exposed, the short tongue and labial palpi leaving the ventral surface of the body largely exposed.

THE COCOON (PL. XV, FIG. 1)

About 1.8 by $1 \mathrm{~mm}$. White, oval, flattened, strongly narrowed to the posterior end where it is stained by a brown dot of the last frass; broadly rounded at the anterior end, where there is a horizontal slit its whole width, for the emergence of the moth, closed before emergence by a few silk threads. The cocoon usually bulges on one side more than the other.

THE ADULT (PL. XV. FIG. 3)

Expanse $2.8 \mathrm{~mm}$. Black, with a slight purple irridescence. Head cream color, including palpi, oceiput and eye-caps; tuft deep ochre or dull tawny. Antennae fuscous. Fore-wing with two palegold fasciae, the more basal one somewhat darker and slightly less iridescent, twice as wide on inner margin as on costa, and with its outer boundary somewhat offset on the fold (see figure); second fascia somewhat widened to inner margin and slightly constricted at middle of wing, slightly wider than first fascia at costa, but much narrower at inner margin. Apex more shining, occasionally appearing silvery in a favorable light. Fringe about apex with a black basal line, the outer part nearly white and strongly contrasting, dorsal fringe mouse-gray. Hind-wing light gray with mouse-gray fringe. Thorax lead-gray, the tegulae somewhat darker. Abdomen fuscous. 
We have come across no description of an old-world Nepticula that could be confused with this. In Miss Braun's key ${ }^{3}$ it will run most nearly to $N$. bifasciella Clemens, from which it will differ by the fact that the ground of the fore-wing is all of one color, and by the much smaller size. The two bands of $N$. epicosma Meyrick '15, from South America, differ in position.

Type locality. Juana Díaz, Porto Rico, Holotype and eight paratypes, Cornell University, type No. 948.

\section{THE MINE (PL: XVI)}

Slender, sinuous, but if straightened out would be on the average rather more than $25 \mathrm{~mm}$. in length; ends in the usual slight enlargement with a crescent-shaped emergence hole on under surface of the leaf. In the first half of the mine the frass is arranged in a zig-zag line of arcs, each arc being composed of half a dozen dots. In the latter half of the mine this changes over into a single continuous line of fluid frass; the transformation being either abrupt or gradual. In weathered mines the zig-zag first portion of the frass line tends to disappear. The mines cross each other freely and infrequently rum into each other.

In fresh leaves on the plant the mines are almost invisible on the upper surface but when the lower surface is examined they may be readily traced since their surface is noticeably raised and in the older portions the mines are slightly reddish or purplish. When the leaves become old and dried the mines become whitish in marked contrast to the darkened leaf surface and are then especially conspicuous on the upper surface.

\section{Life-History}

Pressure of other work and lack of sufficient opportunity to rear moths in confinement have not as yet permitted us to determine the full life-history of the cotton leaf-miner. Some information has however been accumulated.

The egg's themselves have not been found but the egg-shells could be readily located under a high power binocular by tilting the leaves slightly towards the sun-light when they then appeared on the lower surface as tiny glistening dots. This simple method of locating Nepticula eggs was suggested by Prof. C. R. Crosby of Cornell University in his bulletin on the plum leaf-miner, Nepticula slingerlandella Kearfott, (Cornell Univ. Agr. Exp. Sta. Bul. 308, 1911). Egg-laying

\footnotetext{
${ }^{3}$ Nepticulidae of North America. Trans. Am. Ent. Soc. 43: 155, 1917, largely re86,1923 .
} 
has not been observed but probably takes place in the evening or at night as is the case with several lepidopterous leaf-miners, including the coffee leaf-miner (Leucoptera coffeella Guérin) and probably with the plum leaf-miner. The eggs are laid singly on the undersurface of the leaves, and as far as observed in the fork of two veinlets, a portion of the edge of the egg often being somewhat concealed beneath the veinlet, so closely is it applied to the veinlet. A small blackish dot of frass ean usually be seen within the empty egg-shell. The larva upon hatching apparently enters the leaf tissue directly thru the surface of the egg-shell next to the leaf since no break in the chorion is noticeable on the side away from the leaf surface. The mine undoubtedly starts at the egg-shell but is usually indistinguishable for a short distance away from it.

In the laboratory where infested leaves have been confined in jars or boxes, the larvae, when full-grown, have always formed their cocoons on the leaves. These have been attached usually to the underside against a vein and so firmly as to permit dissecting out the pupa with a single needle without tearing the cocoon loose from the leaf. It may be that in nature pupation takes place in the soil. We have been unable to find cocoons on the leaves in the field even in heavily infested cotton. As further evidence of this possibility two or three naked pupae have been found on the surface of a leaf in the laboratory. The length of the pupal stage is apparently about a week to ten days; or at least that is the time elapsing from the formation of the cocoon to the emergence of the adult.

When ready to emerge the pupa works its way forward, splitting the very thin silk at the anterior end of the pupa about one-third the way down. The empty pupa shell projects slightly from the cocoon. Emergence apparently takes place in the early morning, since the moths were found only in the morning in the shell vials in which pupae had been confined and never by late in the afternoon.

\section{Parasites}

Several specimens of a black and of a yellow Chalcis fly have been observed on leaves confined in the laboratory and infested with this leaf-miner. They undoubtedly are parasitic, although this point has not yet been definitely established. The leaf-miner is easily susceptible to parasitism in the mines and undoubtedly further observations will establish parasitism since the coffee leaf-miner also seems to be readily parasitized in Porto Rico. 


\section{Economic Importance}

During the three months this leaf-miner has been under observation it has not been difficult to find cotton fields of one to several acres in extent in the southern part of the Island in which almost literally one hundred percent of the leaves have been infested. Some of the younger and smaller leaves will contain but a single mine while many older and larger ones may have many mines. Apparently, however, little premature shedding of the foliage occurs even on plants which are severely infested. It must be regarded therefore at the present time as merely a minor pest of cotton but of possibly greater potential importance in the future. It is difficult to believe, however, that as considerable infestations as have been observed should not interfere to an appreciable extent with the proper functioning of the leaves with consequent reduction in size and quality of the crop.

Should the insect assume sufficient proportions at any time in the future so as to make remedial measures seem worth while one or two thoro applications of nicotine sulfate ("Black Leaf 40"), 1 part in 800 parts of water, directed against the underside of the leaves would undoubtedly kill a large proportion of the larvae in the mines. This material is used very successfully for the control of the coffee leaf-miner, Leucoptera coffeella Guérin, in Porto Rico in the seed beds. In order to cheapen the cost of the spray as far as possible a considerably greater dilution of the nicotine sulfate could undoubtedly be used by adding a sufficient quantity of Penetrol, a recently discovered very effective activator for nicotine.

\section{EXPLANATION OF PLATES}

Plate XV. (All greatly enlarged)

Fig. 1 Cocoon.

Fig. 2 Full grown larva, side view.

Fig. 3 Moth.

Fig. 4 Pupa, ventral view.

Fig. 5 Pupa, dorsal view.

Fig. 6 Egg.

Plate XVI. (About three-fourths natural size)

Cotton leaves showing old, weathered mines on upper surface. 
PLATE XV
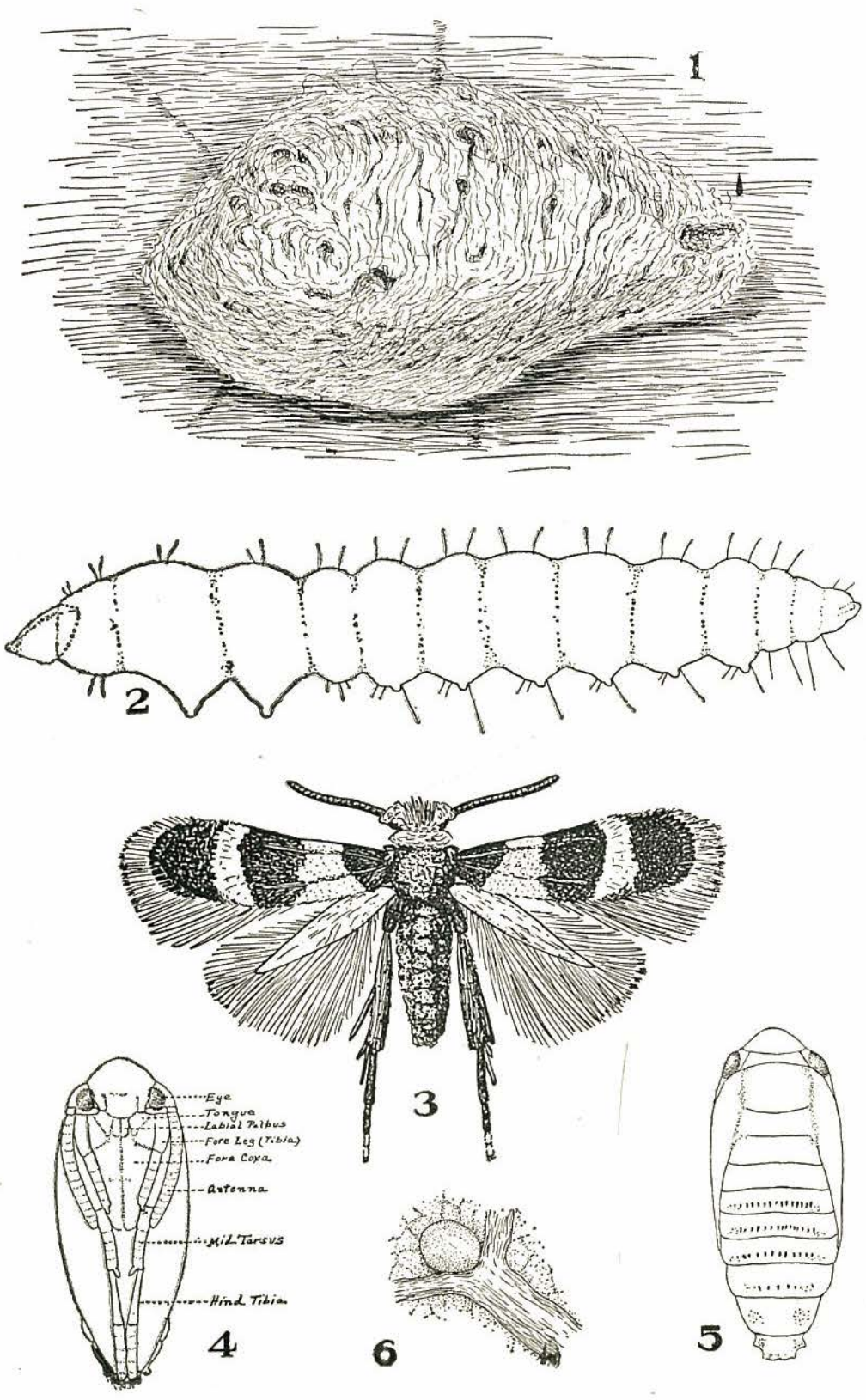


\section{PLATE XVI}

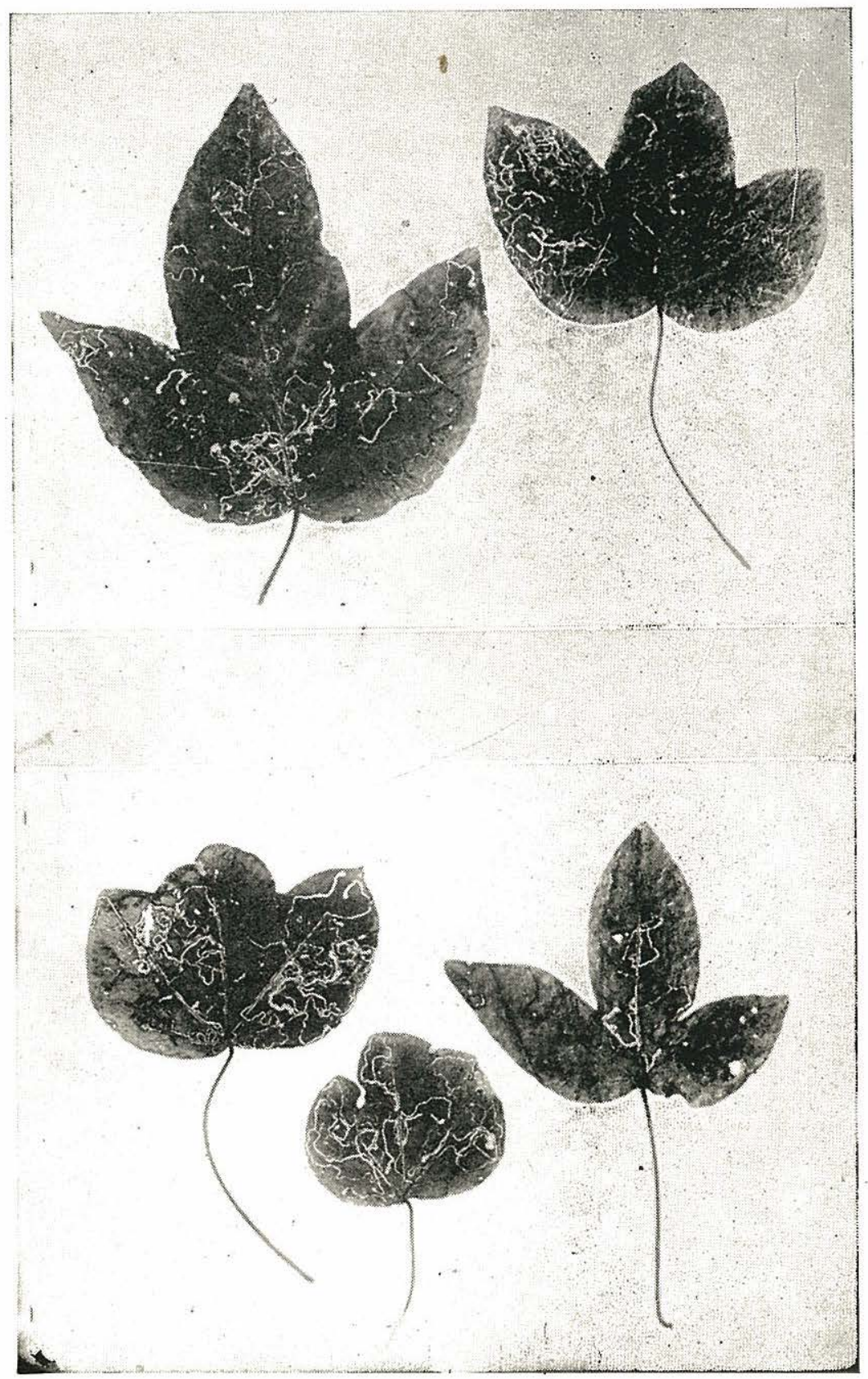

